\title{
Preparation of Polystyrene Spheres Using Surfactant-Free Emulsion Polymerization
}

\author{
Flaviana Yohanala P. T. ${ }^{1}$, Restu Mulya Dewa ${ }^{1}$, Karinda Quarta $^{1}$, Widiyastuti ${ }^{1}$ \& Sugeng Winardi ${ }^{1}$ \\ ${ }^{1}$ Department of Chemical Engineering, Sepuluh Nopember Institute of Technology, Indonesia \\ Correspondence: Widiyastuti, Department of Chemical Engineering, Sepuluh Nopember Institute of Technology, \\ Surabaya, 60111, Indonesia. E-mail: widi@chem-eng.its.ac.id/swinardi@chem-eng.its.ac.id
}

Received: May 4, 2015

Accepted: June 5, 2015

Online Published: June 30, 2015

doi:10.5539/mas.v9n7p121

URL: http://dx.doi.org/10.5539/mas.v9n7p121

\begin{abstract}
Polystyrene spheres have been synthesized using potassium persulphate (KPS) as initiators without using any surfactant or stabilizing agent. Simple mixing method was used to synthesize styrene monomer into polystyrene spheres. The influences of mixing time, ammount of styrene monomers, and ammount of initiators were studied in this research. Size measurement and its distribution were analyzed by Scanning Electron Microscopy (SEM). Monodisperse spheres and verry narrow size distribution are expected in this research. The results showed that the most optimum time to synthesize styrene monomer into polystyrene latex is 6 hours, where biggest and most uniform spheres size were obtained. Meanwhile when ammount of styrene monomers were increased, the diameter of polystyrene spheres were also increased. The biggest and most uniform polystyrene spheres diameter was shown by $14 \%$ volume ratio of styrene monomer. For initiators influence, the smaller diameter of polystyrene spheres were obtained for 0.2 gram KPS than in 0.05 gram KPS. Polystyrene spheres using 0.05 gram KPS also has more uniform size than in 0.2 gram.
\end{abstract}

Keywords: polystyrene spheres, surfactant free, styrene monomer, mixing time, ammount of styrene, ammount of initiators

\section{Introduction}

In recent times, there are so many industries utilised polystyrene as the main material. This polymer has been used in many industries, such as catalysis, immobilization system, packaging and storage industry, etc. This popularity is based from its good properties, such as its rigidity, low water absorbality, low production cost, and good processability (Yoon et al., 2006). Polystyrene is also usually used as template in the synthesis of macropore particles. It is effective because it can be easily removed and available as a homogeneous sphere. This condition makes polystyrene can control pore size by changing its size. It makes further study in the synthesis of polystyrene particles with controllable size becomes needed (Nandiyanto, 2012).

Styrene polymerization using radicalary polymerization mechanism is one of method that has been used to obtain the polystyrene. The formation of macromolecule by free radicals are including three main steps, they are initiation, propagation, and termination of chain growth by either termination or chain transfer. Different type of initiators, organic or inorganic, will give different characteristics to the polymeric materials which synthesized. (Gorsd et al., 2012). The overall reaction describing the styrene polymerization is:

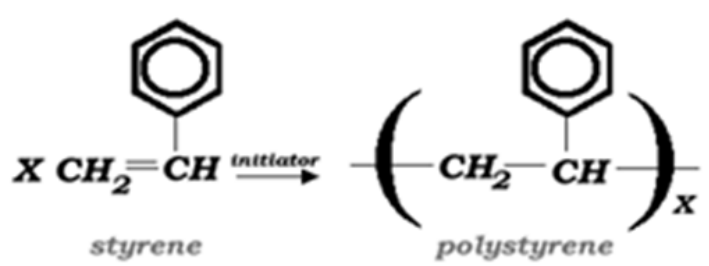

Figure 1. Polymerization Reaction of Polystyrene

Emulsion polymerization is generally used for polymerization of styrene. Emulsion polymerization can produce relatively stable latex (Kim et al., 1992). Water-insoluble monomers would be firstly dispersed into water with a 
small amount of a surfactant. Water-soluble initiator will form radicals when it is heated, because it has weak peroxide bond. These radicals will be the initiator in the chain reaction of the monomers in the water, until they become polymer that grow in the water and become the primary polymer particles. These particles swell with monomers, then the polymer chains initiation continues in the aqueous-phase. After that, the growing polymer radicals are trapped by the existing particles and the polymerization process continues inside the particles. All further polimerization will increase the size of the particles, not the number, until all of the monomers are consumed. The final diameters of particles are depending on all variables in the experimental procedure, but typically are about 50 until $500 \mathrm{~nm}$ (Sunkara et al., 1994).

In order to make polymerization become more economical, this research was aimed to study the polymerization of styrene monomer under surfactant-free condition. The comprehensive studies on the polimerization of styrene monomer under additive-free condition, especially related to its function as template of macropore particle, are not much done yet. The controllable size and monodisperse spheres are expected in this research. Some variables are done to study their influence into polystyrene particle size and particle size distribution.

\section{Method}

\subsection{Polystyrene Spheres Synthesis}

Polystyrene spheres were synthesized using a liquid-phase synthesis method, styrene monomer was simply polymerized in an aqueous solution (pure water), with the absence of additives such as surfactant agents or co-monomer, under potassium persulphate (KPS) as the initiator. Before it was used, the monomer styrene was previously purified by a base solution $(\mathrm{NaOH} 10 \%)$ to remove its inhibitor (Astrini et al.,1997). The polymerization was conducted in the batch-process reactor-system. The reactor consisted of a glass reactor (300 $\mathrm{ml}$ of a four-necked round bottom flask), a magnetic stirrer, a mantle heater, a temperature controller, a reflux condenser equipped with a chiller, and a nitrogen gas inlet (Kim et al., 1992).

Firstly pure water was put into the reactor, then stirred at about $400 \mathrm{rpm}$ and heated at $80^{\circ} \mathrm{C}$. Nitrogen gas was added to remove oxygen from the reactor. When the set temperature was reached, a specific amount of monomer styrene and KPS initiator were added to the reactor. Nitrogen gas was continued to bubble until 15 minutes and then was stopped (Gorsd et al., 2012). The mixtures were subsequently kept at this temperature for specific time, varied between 5 and 7 hours.

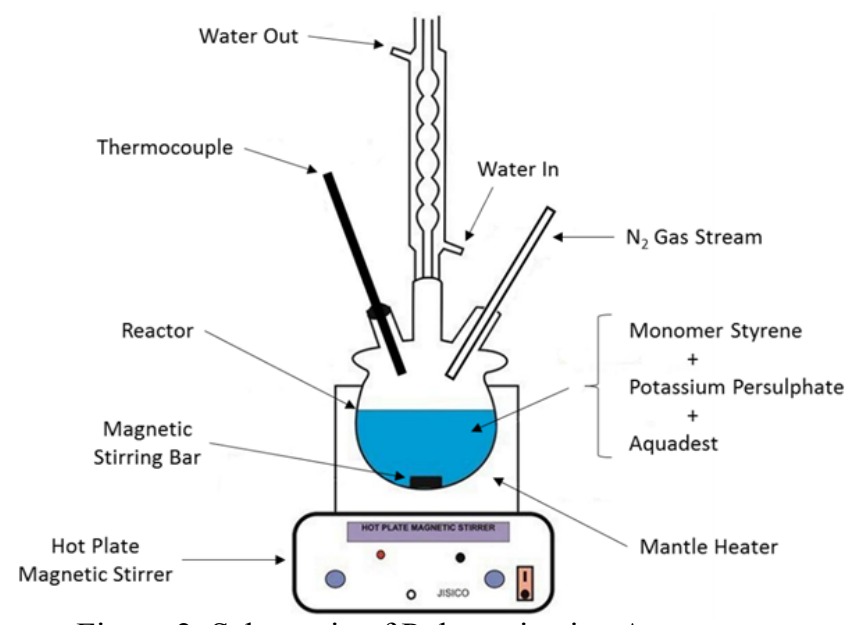

Figure 2. Schematic of Polymerization Apparatus

\subsection{Characterization}

Polystyrene spheres morphological analysis was performed by scanning electron microscopy (SEM). The determination of the sphere diameter, its distribution and the average diameter was carried out from the SEM images of the samples, measuring about 300 until 400 spheres in each images using ImageMIF software. The size of the spheres was measured using Ferret analysis.

\section{Results}

This research was aimed to study the effects of mixing time, styrene concentration, and initiator concentration in the synthesis of monodispersed polystyrene particles. Simple mixing method was used in this research, where polymerization took place in batch reactor equipped with magnetic stirrer. This research used inorganic initiator 
potassium persulphate (KPS) and performed in the absence of any additives, such as stabilizing agents or surfactants.

\subsection{Effect of Mixing Time}

To study the influence of mixing time in the particle size and its distribution, $10 \%(\mathrm{v} / \mathrm{v})$ styrene monomer was mixed with water and 0.05 gr KPS. Mixing time when the mixture were stirred in the reactor was varied 5, 6, and 7 hours. By mixed them, the styrene monomer droplets will be dispersed first before polymerize. Figure 3 shows the SEM images of particles with the impact of mixing time. The result of SEM images showed that polystyrene particles which were obtained has spherical shape and relatively monodispersed. By using ImageMIF software, average diameter and its distribution for each variables can be obtained. The average diameter for variable 5 hours is $206 \mathrm{~nm}$, while for 6 hours is $223 \mathrm{~nm}$, and for 7 hours is $218 \mathrm{~nm}$. Meanwhile figure 4 shows particle distribution for each variables. It was shown that variable 6 hours has the smallest deviation. For next variables, 6 hours of mixing was used as fixed variable.
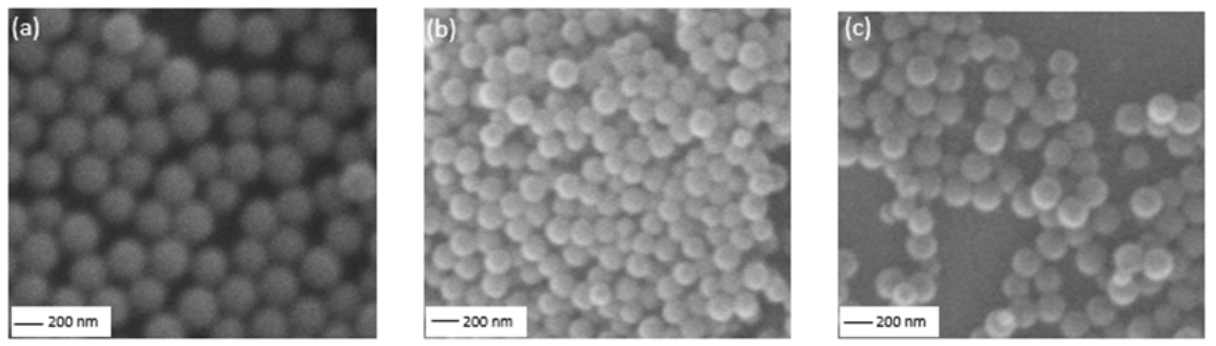

Figure 3. SEM images of polystyrene spheres under different mixing time : (a) 5 hours, (b) 6 hours, and (c) 7 hours
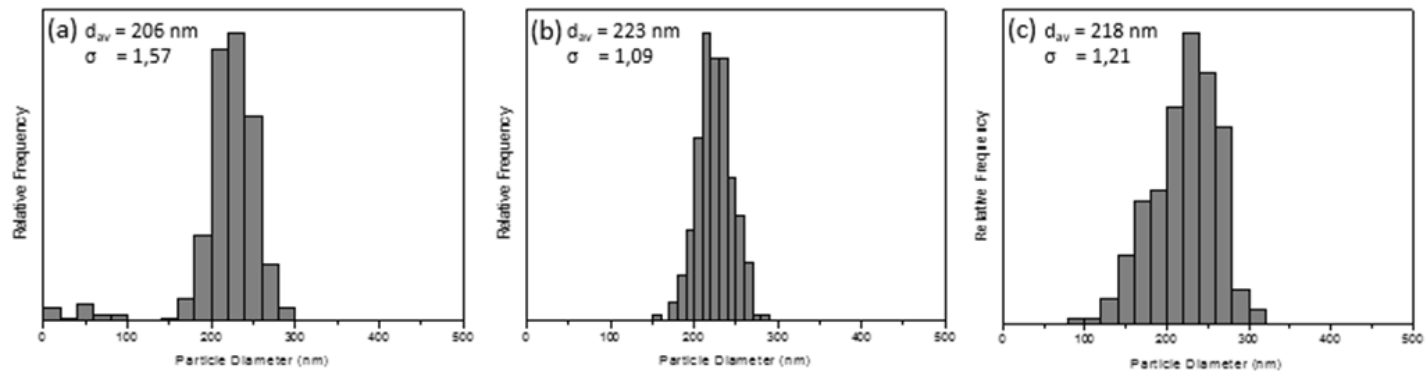

Figure 4. Size distribution of polystyrene spheres under different mixing time: (a) 5 hours, (b) 6 hours, and (c) 7 hours

\subsection{Effect of Styrene Monomer Concentration}

Figure 5 shows SEM images impact of styrene monomer concentration which is added in the initial process of polystyrene spheres polymerization. The styrene monomer concentration was varied between 5\% and 14\% (v/v). Meanwhile the amount of initiator was fixed in $0.05 \mathrm{gr}$, and the mixture was stirred for 6 hours. SEM images show that the shape of polystyrene obtained from all variables are spherical and spread evenly. Meanwhile Figure 6 shows that the average diameter of polystyrene spheres obtained increase when styrene monomer concentration is also increased. The biggest styrene monomer concentration variable, 14\% (v/v), also has the smallest deviation of particle size distribution. It means $14 \%(\mathrm{v} / \mathrm{v})$ variable has the most uniform polystyrene particle size.

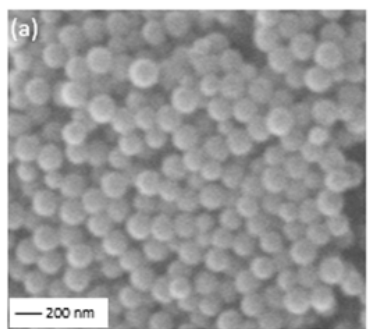

Figure 5. SEM images of polystyrene spheres under different styrene concentration:
$14 \%$

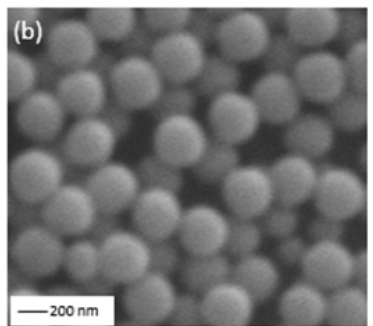

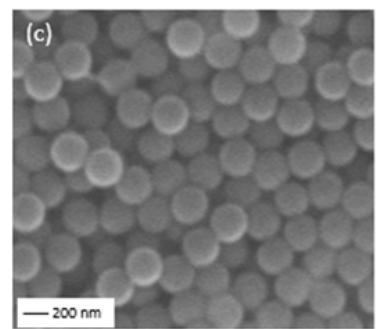

(a) $5 \%$, (b) $10 \%$, and (c) 

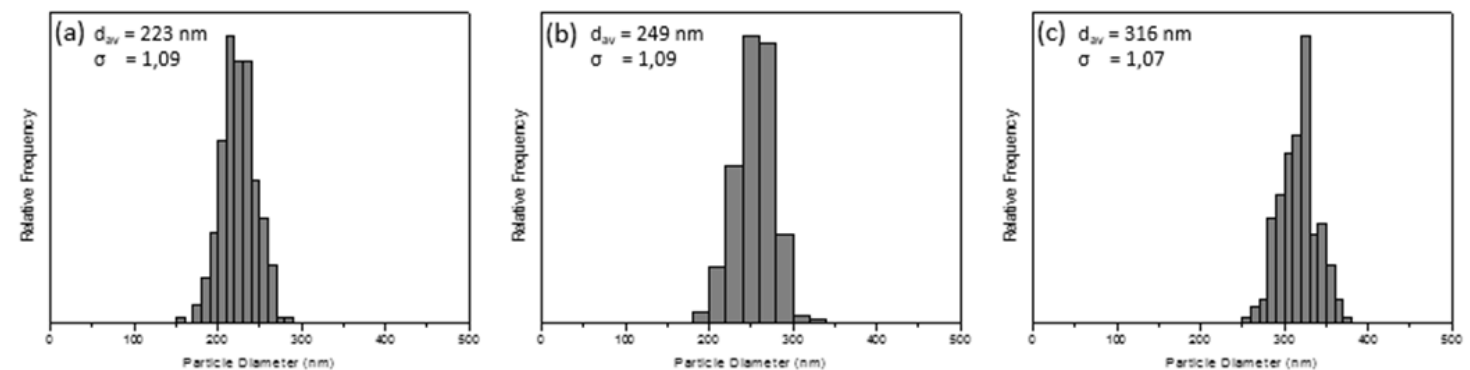

Figure 6. Size distribution of polystyrene spheres under different styrene concentration: 5\%, (b) $10 \%$, and (c) $14 \%$

\subsection{Effect of Initiator Amount}

This research used potassium persulphate (KPS) as the initiator to accelerate polymerization of styrene monomer. KPS is inorganic initiator which can be dissolved in aqueous phase (Gorsd et al., 2012). Figure 7 shows SEM images of polystyrene for each variable of initiator amount. KPS amount was varied into $0.05 \mathrm{gr}$ and $0.2 \mathrm{gr}$. Meanwhile styrene monomer concentration was set constant for $10 \%(\mathrm{v} / \mathrm{v})$ and stirred for 6 hours. The images showed the shape of polystyrene are spherical and spread evenly. Figure 8 shows the average diameter of polystyrene for 0.05 gr amount of initiator is bigger than for 0.2 gr. The particle size distribution graph also shows that smaller amount of initiator variable produces more uniform particle size than the bigger one.
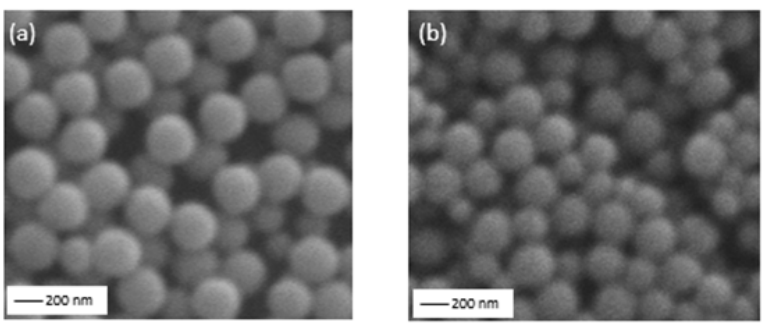

Figure 7. SEM images of polystyrene spheres under different initiator ammount : (a) 0,05 gr and (b) 0,2 gr
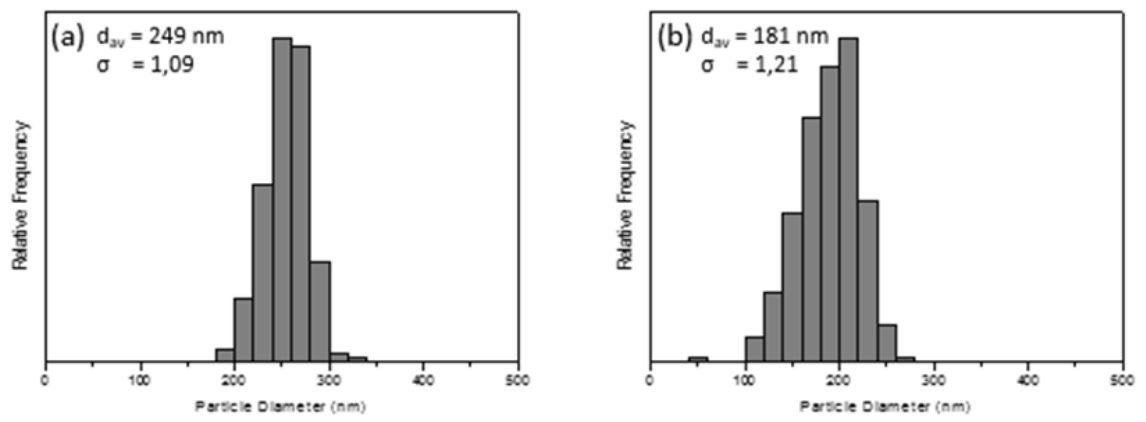

Figure 8. Size distribution of polystyrene spheres under different initiator ammount: 0,05 gr and (b) 0,2 gr

\section{Discussion}

From the result it was showed that the most optimum mixing time is 6 hours, which has the biggest size and the most uniform size of particles. This result is appropriate with what expected, to get monodisperse spherical polystyrene. Particles which obtained from 5 hours variable have the smallest size and the biggest deviation. It can be explained due to the incomplete polymerization reaction for the small time. Meanwhile longer time of mixing can make some particles grow bigger than any other particles. It makes particles size become not uniform and the deviation of particle size distribution becomes bigger. This phenomenon is happened for variable 7 hours.

Meanwhile for styrene concentration effect, the result showed that the average diameter of polystyrene spheres obtained increase and more uniform when styrene monomer concentration is also increased. This phenomena can be explained because the constant amount of dissolved monomer (aqueous-phase monomer) in the aqueous 
solution under additive-free condition to the initial concentration of monomer itself. Monomer will be partially dissolved mostly into monomer droplets (oil-phase monomer). The initiator radicals can easily attack the aqueous-phase monomer and this rate is faster than the rate of monomer diffusion (from oil to aqueous phase), so that there is only limited available active monomer. This condition will retard the nucleation stage. Then, because the Brownian motion of nuclei is slower than other components (Nandiyanto et al., 2010), so that the nuclei is more tended to increase in weight by the interaction and coalescence of initiator radicals and the free monomer, than in number (Nandiyanto et al., 2012). So that, in the bigger monomer concentration there are more free monomers to coalesce and produces bigger particle.

The result also showed that the average diameter of polystyrene for bigger amount of initiator is smaller. The particle size distribution graph also shows that smaller amount of initiator variable produces more uniform particle size than the bigger one. Potassium persulphate (KPS), which was used as initiator, was soluble in aqueous phase and diffused fastly to the monomer droplet. The higher amount of KPS will increase the rate of polymerization process. It makes the nucleation period becomes shorter and produces smaller polystyrene particles (Gorsd et al., 2012).

\section{Conclusion}

Polymerization of styrene monomers was succesfully done using emulsion polymerization under surfactant-free condition. SEM images showed that obtained polystyrene particles have spherical shape and can spread evenly. The result showed that the most optimum mixing time in this polymerization is 6 hours, where the average particle diameter obtained in this variable is the greatest and has the narrowest size distribution. Furthermore, the result also showed that the variation of styrene monomer concentration and amount of KPS initiator can also modify both the average diameter of the obtained particles and its distribution. For a fixed amount of initiator, an increase in the size of the spheres was observed as the styrene monomer concentration increased. The biggest styrene monomer concentration variable also produced the most uniform size of the spheres. Meanwhile, for a fixed styrene monomer concentration, smaller amount of initiator added produced bigger size and also narrower size distribution of the spheres.

Observation of initiator effect can be further developed by using organic initiator, such as 4,4 Azobis 4-Cyanovaleric Acid (ACVA). Different kind of initiator can produce different shape and diameter of polystyrene. Further observation in the application of polystyrene in producing hollow particle also should be done in order to know the stability of template material and its effect in the particle structure.

\section{Nomenclature}

$d_{a v} \quad$ average particle diameter $(\mathrm{nm})$

$\sigma \quad$ deviation of average particle diameter

\section{References}

Astrini, N., \& Tahid, R. (1997). Pembuatan lateks polistirena secara polimerisasi emulsi stirena tanpa emulgator dengan menggunakan aseton. J. IPT., 2(3).

Gorsd, M. N., Blanco, M. N., \& Pizzio, L. R. (2012). Synthesis of Polystyrene microspheres to be used as template in the preparation of hollow spherical materials: Study of the operative variables. Procedia Materials Science, 1, 432-438. http://dx.doi.org/10.1016/j.mspro.2012.06.058

Kim, J. J., Chainey, M., El-Aasser, M. S., \& Vanderhoff, J. W. (1992). Emulsifier-Free Emulsion Copolymerization of Styrene and Sodium Styrene Sulfonate. Journal of Polymer Science: Part A: Polymer Chemistry, 30, 171-183. http://dx.doi.org/10.1002/pola.1992.080300201

Nandiyanto, A. B. D., Hagura, N., Iskandar, F., \& Okuyama, K. (2010). Design of a highly ordered and uniform porous structure with multisized pores in film and particle forms using a template-driven self-assembly technique. Acta Materialia, 58, 282-289. http://dx.doi.org/10.1016/j.actamat.2009.09.004

Nandiyanto, A. B. D., Suhendi, A., Ogi, T., Iwaki, T., \& Okuyama, K. (2012). Synthesis of additive-free cationic Polystyrene particles with controllable size for hollow template applications. Colloids and Surfaces A: Physicochem. Eng. Aspects, 396, 96-105. http://dx.doi.org/10.1016/j.colsurfa.2011.12.048

Sunkara, H. B., Jethmalani, J. M., \& Ford, W. T. (1994). Synthesis of crosslinked poly(styrene- co- sodium styrenesulfonate) latexes. J. Polym. Sci. Part A: Polymer Chemistry, 32, 1431-1435. http://dx.doi.org/10.1002/pola.1994.080320804

Yoon, S. B., Kim, J. Y., Park, S. G, Lee, C. M., \& Yu, J. (2006). Template synthesis of nanostructured silica with 
hollow core and mesoporous shell structures. Current Applied Physics, 6, 1059-1063. http://dx.doi.org/10.1016/j.cap.2005.07.019

\section{Copyrights}

Copyright for this article is retained by the author(s), with first publication rights granted to the journal.

This is an open-access article distributed under the terms and conditions of the Creative Commons Attribution license (http://creativecommons.org/licenses/by/3.0/). 